\title{
Bandwidth knowledge of results persists on motor skills acquisition
}

\author{
Madson Pereira Cruz¹, Rodolfo Novellino Benda ${ }^{1}$, Maria Flávia Soares Pinto Carvalho², \\ Guilherme Menezes Lage ${ }^{1}$, Maria Teresa Cattuzzo ${ }^{3}$, Herbert Ugrinowitsch ${ }^{1 *}$

\begin{abstract}
The aim of this study was to investigate the short and long-term effects of the bandwidth KR in learning of the absolute and relative dimensions of a motor skill. Twenty-two undergraduate students divided into two groups: G15 who received KR when the relative error exceeded 15\%; and G0, with KR after every trial. The study consisted of an acquisition phase, and the volunteers practiced 100 trials with a target time of 850 $\mathrm{ms}$ and relative of $22.2 \%, 44.4 \%$ and $33.3 \%$ between the first and second, second and third, third and fourth keys, respectively. This phase, KR related to relative time (relative error) was provided according to the group. KR of total target time was available to both groups after all trials. Three retention tests with ten trials were conducted 10 minutes, 24 hours and one week after the acquisition phase. The results showed that G15 had a smaller relative error than G0. This study allows concluding that bandwidth KR in relation relative time error showed its effects in the consistency of relative time. These effects persisted even after seven days after the acquisition phase in a delayed retention test.

Keywords: feedback, transitory effects, permanent effects, long term retention, motor skill.
\end{abstract}

\section{INTRODUCTION}

Knowledge of results (KR) is a type of feedback that provides information related to the success of the goal of the task. The KR provided after every trial conducted to worst performance when compared to the reduced frequency of KR (Vieira, Ugrinowitsch, Gallo, Carvalho, Fonseca \& Benda, 2014) or even with bandwidth KR (Coca-Ugrinowitsch, Benda, Aburachid, Andrade, Greco, Karl-Menzel \& Ugrinowitsch, 2014). Bandwidth KR implies in establishing one margin of error tolerance around the goal of the task and the quantitative information about the error is provided only when the error is outside the bandwidth (Salmoni, Schmidt \& Walter, 1984). If the error is inside the bandwidth, quantitative information is not provided, but the learner knows that it was a correct trial (Sherwood, 1988). When performance is outside of the established bandwidth, then quantitative information about the error is provided. One particularity of the bandwidth $\mathrm{KR}$ is this quantitative information based on the learner's performance (Lai \& Shea, 1999; Sherwood, 1988; Ugrinowitsch, Coca Ugrinowitsch, Benda \& Tertuliano, 2010).

Some results showed that bandwidth KR increased performance consistency compared to no bandwidth KR at all (Coca Ugrinowitsch, Benda, Aburachid, Andrade, Greco, Menzel \& Ugrinowitsch, 2014; Junqueira, Benda, Santos, Lage, Vieira, Carvalho \& Ugrinowitsch, 2015; Salmoni, Schmidt \& Walter, 1984; Ugrinowitsch, Fonseca, Carvalho, Profeta \& Benda, 2011). From these studies, Lai \& Shea (1999) and Ugrinowitsch, Coca Ugrinowitsch, Benda \& Tertuliano (2010) found that the wider bandwidth conducted to better performance on learning tests than narrow or even no bandwidth at all but Junqueira et al. (2015) found higher performance accuracy for narrow bandwidth.

One explanation of the benefits of bandwidth $\mathrm{KR}$ is the combination of quantitative information about error magnitude and direction (when performance is outside the established bandwidth) with qualitative information (i.e., no

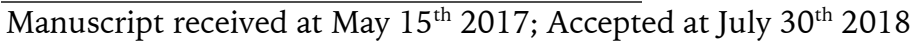

${ }^{1}$ Universidade Federal de Minas Gerais, Belo Horizonte, Brasil

${ }^{2}$ Instituto Federal Catarinense, São Bento do Sul, SC, Brasil

${ }^{3}$ Universidade de Pernanbuco, Recife, PE, Brasil

*Correspondingauthor: herbertu@ufmg.br
} 
KR information when performance is inside the bandwidth) (Badets \& Blandin, 2005; Coca Ugrinowitsch et al., 2014; Goodwin \& Meeuwsen, 1995). When KR is not provided the trial is considered correct and, consequently, the planned action is not changed for the next trial. The combination of quantitative and qualitative KR seems to be the key point to explain the bandwidth $\mathrm{KR}$ benefits, guiding the learners to a correct performance (provide by KR) leading them to stabilize the behavior (provide by the absence of KR) as well (Badets \& Blandin, 2005; Lee \& Carnahan, 1990). To provide KR using bandwidth can be useful in situations which error is resultant from the internal noise that causes performance variability. In this condition, the learner does not have control of the error because it does not occur due to wrong planning and execution of the action, but due inherent variability of neuromuscular system (Winstein \& Schmidt, 1990). Thus, the bandwidth KR would not take into account errors caused by noise of the neuromuscular system and, consequently, unnecessary corrections would not be made. The $\mathrm{KR}$ is positive when related to incorrect formulation of the action plan since it helps to create a correct reference about the task for subsequent executions (Tani, 1989). However, this same information is negative when the cause of the error is due to the variability inherent in the neuromuscular system, because results in changing a correct action planning.

Consequently, the bandwidth KR may favor consistent behavior because $\mathrm{KR}$ is not given when performance is within the tolerance limit on error. This statement is supported by the higher performance consistency of bandwidth KR when compared to no bandwidth at all (Badets \& Bladin, 2005; Lee \& Carnahan, 1990; Sherwood, 1988). These benefits over skill acquisition should be persistent beyond learning phase, lasting hours or even weeks. Despite there is no specific time, the persistence of the benefits should remain when tested on delayed retention/transfer tests (Salmoni, Schmidt \& Walter, 1984). Different intervals between acquisition phase and tests have been adopted such as 5 minutes (Lee \& Carnahan, 1990; Sherwood, 1988), 10 minutes (Fairbrother,
Magnuson \& Shea, 2004; Goodwin \& Meeuwsen, 1995; Lee \& Maraj, 1994), 20 minutes (Fairbrother, Magnuson \& Shea, 2004), 24 hours (David \& Wulf, 2000; De Groot, De Winter, Garcia, Mulder \& Wieringa, 2011; Lai \& Shea, 1999; Shea \& David, 2001) or 48 hours (Fairbrother, Magnuson \& Shea, 2004; Goodwin \& Meeuwsen, 1995). The bandwidth KR benefits have been shown when tests were applied 10 minutes, 24 and/or 48 hours after acquisition phase. However, due to the short interval between acquisition phase and the tests, it can be difficult to differentiate transient to permanent effects of practice (Newell, 2007).

When practice with bandwidth KR is enough to induce skill acquisition, there are representations of task practiced in memory, one memory required to start the task and other memory used to compare whether there is any difference between the planned and performed action (Salmoni, Schmidt \& Walter, 1984). In tests situations, when KR is withdrawn, the skill practiced could be recalled (Schmidt, 1975). In a revision study, Salmoni, Schmidt \& Walter (1984) reported that reduced frequency of KR showed good performance only during the seven days delayed tests. Therefore, bandwidth KR could also be beneficial in a delayed retention test. Thus, the aim of this study was to investigate the short and long-term effects of the bandwidth KR in the acquisition of the absolute and relative dimensions of a motor skill. The hypothesis is that bandwidth KR will show higher consistency during long-term retention test.

\section{METHOD}

\section{Participants}

Twenty-two university students (11 men and 11 women), 18 to 35 years old: $M=24,92 \pm 0.82$, without experience in the proposed task participated as volunteer in this experiment. The study was approved by the Ethical Committee of the Universidade Federal de Minas Gerais ( ${ }^{\circ}$ ETIC 525/07), and it was conducted in accordance with APA Ethical Procedures. 


\section{Measures}

Task and Instrument

Competition The aim of the task consisted of pressing the keys 2, 8, 6, 4 (in this specific sequence) using the index finger, under the target time of $850 \mathrm{~ms}$ and relative time of $22.2 \% ; 44.4 \%$ e $33.3 \%$, respectively. The relative time was adopted as structure measure and the total time as parameters measure, the same procedure adopted by Lage et al. (2007) and Lai \& Shea (1999). In other words, volunteers should use $22.2 \%$ of total time $(850 \mathrm{~ms})$ to press from the key 2 to 4 and so on. The instrument consisted of one laptop, one screen, and one numerical keyboard (Figure 1) that were positioned over a table. Specific software was constructed for data collection and storage.

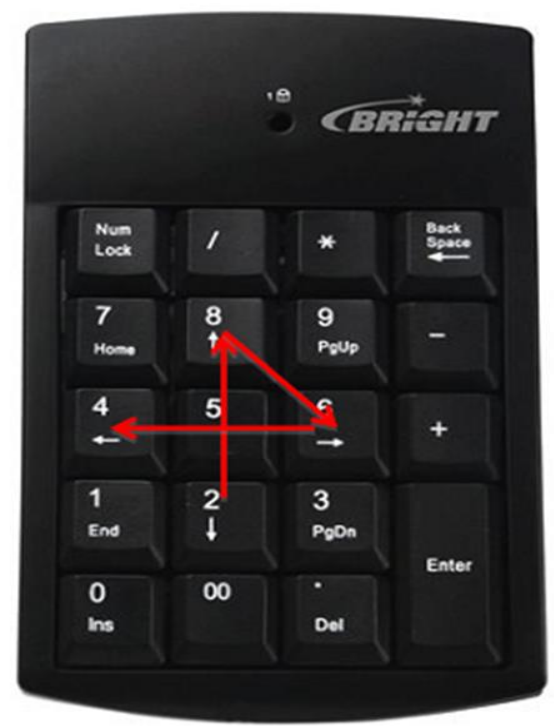

Figure 1. Instrument used in the experiment, similar to Lai and Shea (1999).

\section{Experimental Design}

The whole experiment consisted of acquisition phase and three retention tests. During the acquisition phase, participants performed 100 trials pressing the keys 2, 8, 6, 4 with the target time of $850 \mathrm{~ms}$ under the relative time of $22.2 \%, 44.4 \%$ and $33.3 \%$, respectively. After 10 minutes of the acquisition phase, it was run the first retention test with 10 trials with the same target time and same relative time of that adopted during the acquisition phase. Similar tests were replicated $24 \mathrm{~h}$ later and one week after the acquisition phase. KR was not provided during the tests.
The participants were randomly distributed but counterbalanced by sex into two groups: $0 \%$ of KR bandwidth (G0) and wide of $15 \%$ of KR bandwidth (G15). This percentage is the same observed in previous studies of motor skills (Lai and Shea, 1999; Ugrinowitsch et al., 2010). During acquisition phase, KR about relative error (RE) was provided to G0 after every trial, and to G15 it was provided when the error in performance exceeded $15 \%$ in relation to the goal of the task. However, when performance was inside the bandwidth, no KR was provided, and the volunteer knew that it was considered a correct trial. The $\mathrm{KR}$ related total time error (absolute error) was available to both groups after every trial.

\section{Procedures}

Before the experiment, the participants read and signed the agreement term with information related to the research, and they received instructions related to the instrument and the goals of the task. The experiment was run individually in a quiet room. The participant sat in a chair and adjusted it in a comfortable position, with the right hand on the numeric keyboard and in front of the screen, in which was provided KR about absolute and relative error, when necessary. The KR about the relative error (i.e., structure measure) was available on the screen approximately $5 \mathrm{~s}$ after the trial. A laptop was in front of the researcher to control the whole experiment.

The volunteer was informed about the goal of the task and asked to be as accurate as possible to the total time $(850 \mathrm{~ms})$ and the relative time (22.2\%, 44.4\%, 33.3\%). After the appearance of the $\mathrm{KR}$ on the screen, the researcher indicated that the next attempt should start.

The effects of bandwidth KR were analyzed over absolute error (AE) and relative error (RE), in acquisition phase and retention tests. The AE was adopted as a measure of parameter and RE as a measure of movement structure. The two measures were adopted as performance accuracy and the standard deviation of both measures as performance consistency. The RE was calculated in relation to the sum of the differences between the proportion in time performed in each 
segment and the goal of each segment (S): RE = $(\mathrm{S} 1-22.2+\mathrm{S} 2-44.4+\mathrm{S} 3-33.3) \times 100$. The proportions of each segment were calculated by the equation: $\mathrm{Sn}=$ (time spent in each segment / total movement time) X 100 (Lage et al., 2007; Lai \& Shea, 1999). The absolute error was calculated by the difference between the total target time $(850 \mathrm{~ms})$ and the performed total time.

\section{Statistical analysis}

All data were organized in blocks of 10 trials. The Shapiro Wilk test indicated the sample followed a normal distribution, so data were analyzed by two way ANOVA (2 Groups x 10 Blocks) on acquisition phase. Retention tests were analyzed by a two way ANOVA (2 Groups $x$ 3 Blocks). Tukey test was adopted for pair comparison, and the level of significance adopted was $\mathrm{p} \leq 0.05$.

\section{RESULTS}

\section{Absolute Error (AE)}

All data wereIn acquisition phase (Figure 2a), there was significant difference between blocks, $\left(\mathrm{F}_{9,180}=8.343, \mathrm{p}=0.001\right)$. The Tukey test detected that accuracy increased (i.e., AE diminished) from the first to the fourth and to tenth blocks $(p=0.002)$. There were no significant differences neither between groups, $\left(\mathrm{F}_{1,20}=0.045, \mathrm{p}=0.835\right)$ nor main interactions, $\left(\mathrm{F}_{9,180}=1.840, \mathrm{p}=0.064\right)$.

In retention tests (Figure $2 \mathrm{~b}$ ), there was no significant differences either between groups, $\left(\mathrm{F}_{1,20}=0.276, \mathrm{p}=0.605\right)$, blocks, $\quad\left(\mathrm{F}_{2,40}=2.122\right.$, $\mathrm{p}=0.133)$ or main interactions, $\left(\mathrm{F}_{2}, 40=1.198\right.$, $\mathrm{p}=0.312)$.

\section{Relative Error (RE)}

In acquisition phase (Figure $2 c$ ), there was significant difference between blocks, $\left(\mathrm{F}_{9,180}=11.703, \mathrm{p}=0.001\right)$. Tukey test detected that the structure accuracy increased (i.e., RE diminished) from the first to the fourth and to tenth blocks $(p=0.001)$. Moreover, accuracy increased from the second block to the sixth to tenth blocks $(p=0.003)$. There was no significant difference neither between groups, $\left(F_{1,20}=0.181\right.$, $\mathrm{p}=0.675)$ nor main interactions, $\left(\mathrm{F}_{9,180}=1.102\right.$, $\mathrm{p}=0.364$ ).

In retention tests (Figure 2d), there was no significant difference between groups, $\left(\mathrm{F}_{1,20}=1.163, \mathrm{p}=0.294\right)$, and tests, $\left(\mathrm{F}_{2,40}=1.149\right.$, $\mathrm{p}=0.327)$ or main interactions, $\quad\left(\mathrm{F}_{2,40}=0.263\right.$, $\mathrm{p}=0.770$ ).

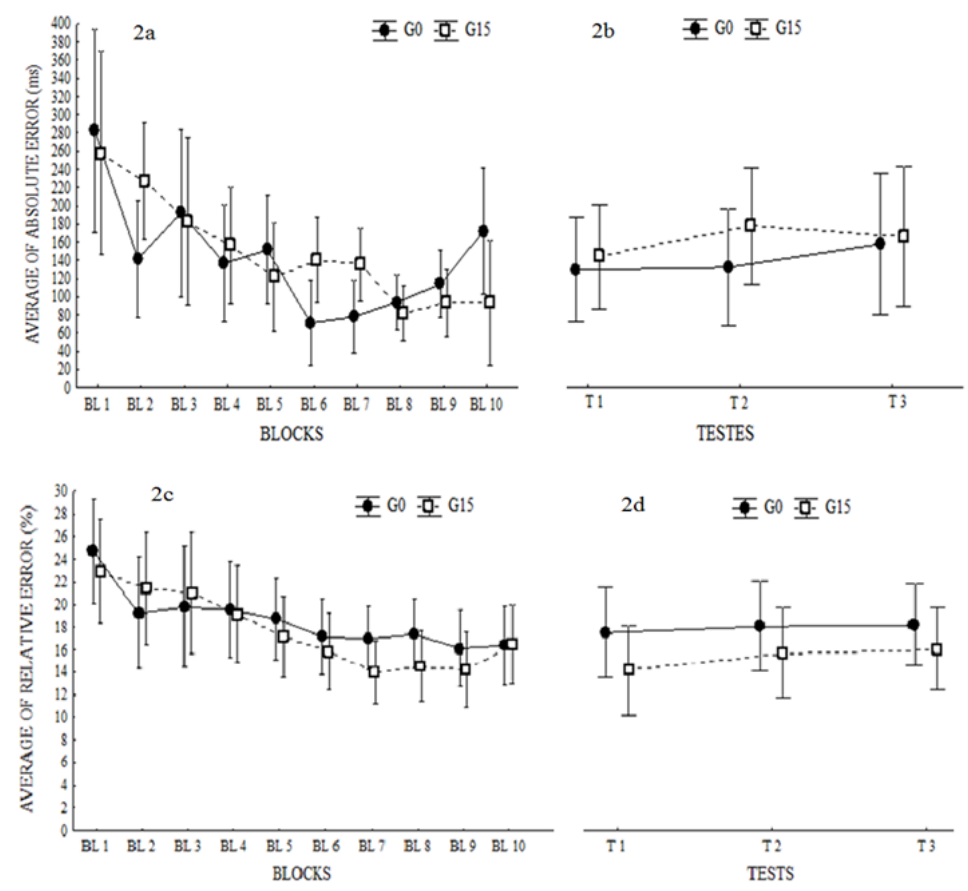

Figure 2. a) Average of AE during acquisition phase; b) Average of AE in the retention test; c) Average of RE during acquisition phase; d) Average of RE in the retention test. The vertical bars denote $95 \%$ of confidence interval. 


\section{Standard Deviation of $A E$}

In acquisition phase (Figure $3 \mathrm{a}$ ), there was significant difference between blocks, $\left(\mathrm{F}_{9,180}=8.541, \mathrm{p}=0.001\right)$. The Tukey test detected that performance consistency increased from the first to the third and tenth blocks $(p=0.003)$, and from the second to the sixth to tenth blocks $(p=0.003)$. There was also significant interaction, $\left(F_{9,180}=3.558, p=0.001\right)$. The Tukey test detected that only during the first block, G15 was more consistent than G0 $(p=0.001)$. There were no significant differences between groups, $\left(\mathrm{F}_{1,20}=0.492, \mathrm{p}=0.491\right)$.

In retention tests (Figure $3 \mathrm{~b}$ ), there was no significant difference between groups, $\left(\mathrm{F}_{1,20}=0.002, \mathrm{p}=0.962\right)$ and, blocks, $\left(\mathrm{F}_{2,40}=0.076\right.$, $\mathrm{p}=0.927)$ or main interactions, $\left(\mathrm{F}_{2,40}=2.106\right.$, $\mathrm{p}=0.135)$.

\section{Standard Deviation of RE}

In acquisition phase (Figure 3c), there was significant difference between blocks, $\left(F_{9,180}=7.769, p=0.001\right)$. Tukey test detected that the structure consistency increased (i.e., standard deviation decreased) from the first to the third to tenth blocks $(p=0.001)$ and from the second to the ninth and tenth blocks $(p=0.005)$. There was neither significant difference between groups, $\left(\mathrm{F}_{1,20}=4.187, \mathrm{p}=0.054\right)$ nor main interactions, $\left(\mathrm{F}_{9,180}=0.605, \mathrm{p}=0.791\right)$.

In retention tests (Figure $3 \mathrm{~d}$ ), there was no significant difference between blocks, $\left(\mathrm{F}_{2,40}=0.161, \mathrm{p}=0.852\right)$ or main interactions, $\left(\mathrm{F}_{2,40}=1, \quad 058, \quad \mathrm{p}=0.357\right)$. However, $\mathrm{G} 15$ presented higher consistency than G0, $\left(\mathrm{F}_{1,20}=8.024, \mathrm{p}=0.02\right)$.
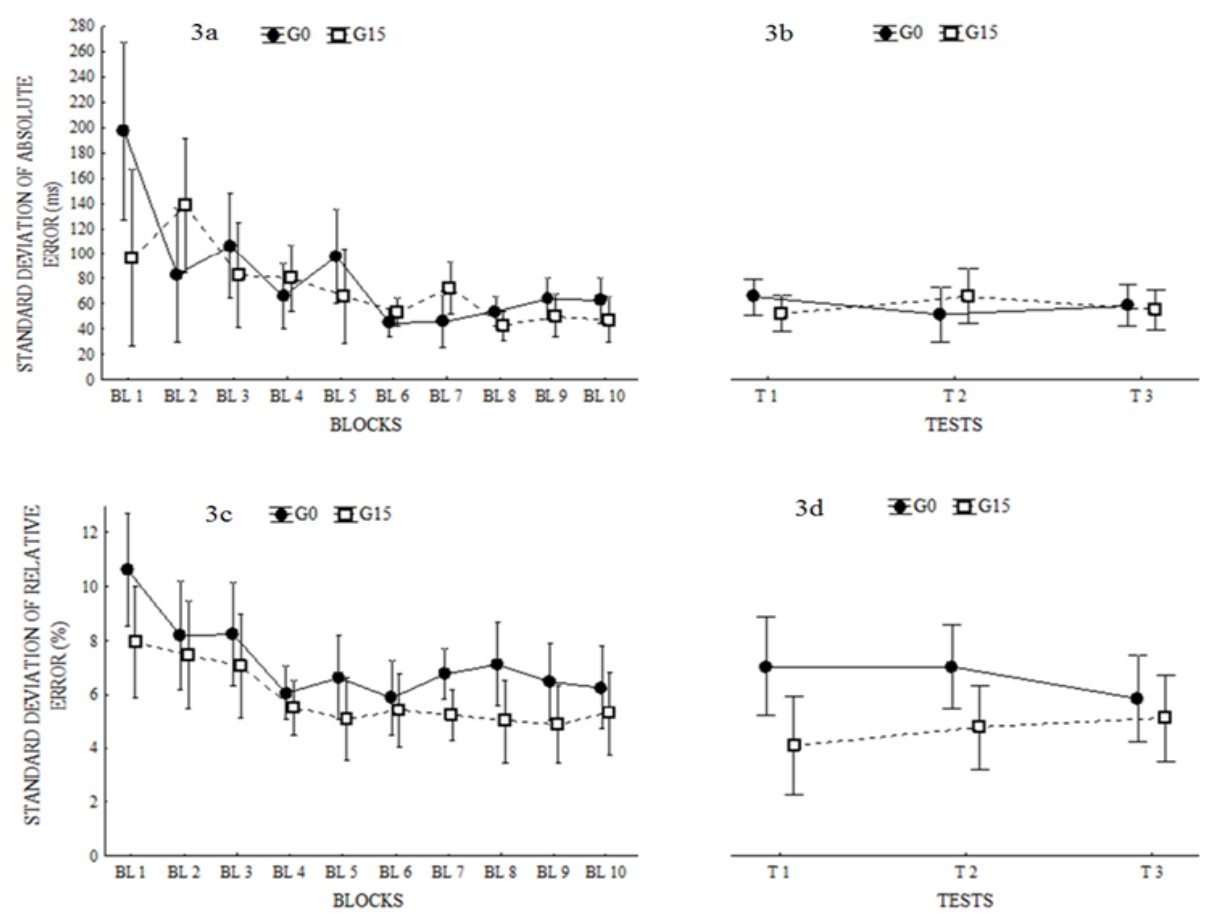

Figure 3. a) Standard deviation of AE during acquisition phase; b) Standard deviation of AE in the retention test; c) Standard deviation of RE during acquisition phase; d) Standard deviation of RE in the retention test. The vertical bars denote $95 \%$ of confidence interval.

\section{DISCUSSION}

Bandwidth KR improves skill acquisition, but the persistency of this effect was not tested. We investigated the short and long-term effects of the bandwidth $\mathrm{KR}$ in learning of the absolute and relative dimensions of a motor skill. We manipulated bandwidth $\mathrm{KR}$ about the relative time structure and parameters. The hypothesis tested was that the bandwidth would have higher consistency during long-term retention test than control condition (i.e., bandwidth $0 \%$ ), which was partially confirmed.

During the process of learning (i.e., acquisition phase), both conditions increased the 
performance accuracy of the structure and parameters. The provided information about movement structure and parameters during acquisition phase was effective to improve both, the structure and the parameters selection (Lage et al., 2007). Moreover, the bandwidth condition started the acquisition phase with higher consistency on parameters performance, but with practice, they presented similar accuracy, results also observed in previous studies (Graydon, 1997; Schiffman, Luchies, Richards \& Zebas, 2002; Sherwood, 1988), as well as the structure variability. So, we can say that bandwidth and control conditions similarly increased consistency.

However, the most important effects were observed during retention and/or transfer tests (Salmoni, Schmidt \& Walter, 1984). The performance accuracy showed similarity between bandwidth and control conditions. In accordance to guidance hypothesis, $100 \% \mathrm{KR}$ prevent subject to use intrinsic feedback due to larger amount of extrinsic information (De Groot et al., 2011; Salmoni et al., 1984; Ugrinowitsch et al., 2010), which can cause dependency. Probably because using extrinsic feedback is easier to use those intrinsic mechanisms of error detection and correction the performance deteriorates when KR is not available, such as in tests situations. However, that expectation was not confirmed. These results are opposite to other studies that showed better performance in accuracy of bandwidth KR groups in relation to feedback after every trial (Goodwin \& Meeuwsen, 1995; Lee \& Maraj, 1994; Coca Ugrinowitsch et al., 2014). For Ugrinowitsch et al., (2010), probably the effect of bandwidth feedback is related to the dimension of the task manipulated during learning (i.e., structure or parameters of the skill).

Furthermore, since performance inside bandwidth means no quantitative $\mathrm{KR}$, the benefit of bandwidth should be observed over the consistency of performance (Ugrinowitsch et al., 2010) and might be sensitive to the need of the learner (Lee \& Carnahan, 1990). That lack of quantitative feedback means that the trial is considered correct and the participant does not have to make corrections on the planned action, which becomes more consistent (Sherwood,
1988). The consistency of the parameters (i.e., AE) was similar between the two conditions. Although the consistency hypothesis (Schmidt, 1991; Winstein \& Schmidt, 1990) proposed that the wide bandwidth would be more consistent than the bandwidth of $0 \%$ of KR (Badets \& Blandin, 2005; Lee \& Carnahan, 1990; Sherwood, 1988; Ugrinowitsch et al., 2010), that provided $\mathrm{KR}$ in relation to absolute dimension. We provided feedback related to relative dimension, which may have reflected in no difference on consistency performance of the parameters.

The bandwidth provided about the movement structure (i.e., RE) resulted on higher consistency than control condition on retention test, and this consistent behavior was persistent even after one week without practice indicating that motor learning was persistent for a long term (Newell, 2007). This persistence indicates longterm storage (Salmoni, Schmidt \& Walter, 1984). We also can state that bandwidth KR helped in a representation of the task in memory and this representation was used to plan consistent actions, whose effects remained seven days after the first retention test. This learning consistency is in accordance with studies that showed more consistent behavior of bandwidth KR group than control group (Badets \& Blandin, 2005; Lee \& Carnahan, 1990; Ugrinowitsch et al., 2010) and supports the consistency hypothesis (Schmidt, 1991; Winstein \& Schmidt, 1990). The performance inside the established bandwidth results in no KR after the trial and is not necessary to make adjustments for the next trial, which makes performance more consistent. Although there was no difference in the RE consistency during the learning phase, the repetition of the action plan resulted in higher consistency during retention tests.

The higher consistency on relative dimension and its persistence after seven days without practice show specificity between the information of bandwidth provided (RE) and the dimension of the task that is learned (i.e., structure of the skill). Future studies investigating short and long-term effects of bandwidth KR, providing information in relation to relative as well absolute dimensions of motor skill are necessary. 
This study manipulated only relative error. However, since motor skills have structure (relative time) and parameters (total time), it is important future studies to manipulate total time and investigate the persistency over motor skills.

\section{CONCLUSION}

The results of this study allow concluding that bandwidth $\mathrm{KR}$ in relation relative time error improves the relative time consistency, indicating specificity between the nature of feedback provided (i.e., structure of the skill) and the learning of that dimension of the task. These effects persisted in a delayed retention test. More studies that investigate if there is that relationship between the nature of feedback and the learning of that specific dimension are necessary.

\section{Acknowledgments:}

Nothing to declare.

\section{Conflict of interests:}

Nothing to declare.

\section{Funding:}

Nothing to declare.

\section{REFERENCES}

Badets, A., \& Blandin, Y. (2005). Observational learning: effects of bandwidth knowledge of result. Journal of Motor Behavior, 37, 211-216.

Coca Ugrinowitsch, A. A., Benda, R. N., Aburachid, L. M., Andrade, A. G. P., Greco, P. J., Menzel, H. J. K., \& Ugrinowitsch, H. (2014). Bandwidth knowledge of results on the learning of the saloon dart throwing task. Perceptual and Motor Skill, 118, 462-474.

De Groot, S., De Winter, J. C. F., García, J. M. L., Mulder, M. \& Wieringa, P. A. (2011). The effect of concurrent bandwidth feedback on learning the lane-keeping task in a driving simulator. Human Factors, 53, 50-62.

Goodwin, J. E., \& Meeuwsen, H. J. (1995). Using bandwidth knowledge of results to alter relative frequencies during motor skill acquisition. Research Quarterly for Exercise and Sport, 66, 99-104.

Graydon, J., Paine, L., Ellis, C., \& Threadgold, R. (1997). Comparison of bandwidth knowledge of results and the relative frequency effect in learning a discrete motor skill. Journal of Human Movement Studies, 32, 15-28.

Junqueira, A. M. H., Benda, R. N., Santos, S. P., Lage, G. M., Vieira, M. M., Carvalho, M. F. P., \& Ugrinowitsch, H. (2015) Thin Bandwidth Knowledge of Results (KR) Improves Performance Consistency on Motor Skill Acquisition. American Journal of Sports Science, 3, 115-119.

Lage, G. M., Alves, M. A. F., Oliveira, F. S., Palhares, L. R., \& Benda, R. N. (2007). The combination of practice schedules: effects on relative and absolute dimensions of the task. Journal of Human Movement Studies, 52, 21-35.

Lai, Q., \& Shea, C.H. (1999). Bandwidth knowledge of results enhances generalized motor program learning. Research Quarterly for Exercise and Sport, 70, 79-84.

Lai, Q., Shea, C. H., Wulf, G., \& David L. W. (2000). Optimizing generalized motor program and parameter learning. Research Quarterly for Exercise and Sport, 71, 349-356.

Lee, T. D., \& Carnahan, H. (1990). Bandwidth knowledge of results and motor learning: more than just a relative frequency effect. The Quarterly Journal of Experimental Psychology, 42A, 777-789.

Lee, T. D., \& Maraj, B. K. V. (1994). Effects of bandwidth goals and bandwidth knowledge of results on motor learning. Research Quarterly for Exercise and Sport, 65, 244-249.

Magnuson, C. E., Shea, J. B., \& Fairbrother, J. T. (2004). Effects of repeated retention tests on learning a single timing task. Research Quarterly for Exercise and Sport, 75, 39-46.

Salmoni, A. W., Schmidt, R. A., \& Walter, C. B. (1984). Knowledge of results and motor learning; a review and critical reappraisal. Psychological Bulletin, 95, 355-386.

Schmidt, R. A. (1975). A schema theory of discrete motor skill learning. Psychological Review, 82, 225260.

Schiffman, J. M., Luchies, C.W., Richards, L. G., \& Zebas, C. J. (2002). The effects of age and feedback on isometric knee extensor force control abilities. Clinical Biomechanics, 17, 486-493.

Sherwood, D. E. (1988). Effect of bandwidth knowledge on movement consistency. Perceptual and Motor Skills.66, 535-547.

Tani, G. (1989). Significado, detecção e correção do erro de performance no processo ensinoaprendizagem de habilidades motoras. Revista Brasileira de Ciência e Movimento, 3, 50-58.

Ugrinowitsch, H., Coca Ugrinowitsch, A. A., Benda, R. N., \& Tertuliano, I. W. (2010). Effect of bandwidth knowledge of results on the learning of a grip force control task. Perceptual and Motor Skills, 111, 643-653.

Ugrinowitsch, H., Fonseca, F. S., Carvalho, M. F. S. P., Profeta, V. L. S., \& Benda, R. N. (2011). Efeitos de faixas de amplitude de CP na aprendizagem do saque tipo tênis do voleibol. Motriz, 17, 82-92. 
$114 \mid$ MP Cruz, RN Benda, MFS Carvalho, GM Lage, MT Cattuzzo, H Ugrinowitsch

Vieira, M. M, Ugrinowitsch, H., Gallo, L. G., Carvalho, M. F. S. P., Fonseca, M. A., \& Benda, R. N. (2014). Effects of summary knowledge of results in motor skills acquisition. Revista de Psicología del Deporte, 23, 9-14.
Winstein, C. J., \& Schmidt, R. A. (1990). Reduced frequency of knowledge of results enhances motor skill learning. Journal of Experimental Psychology: Learning, Memory and Cognition, 16, 677691.

All content of Journal Motricidade is licensed under Creative Commons, except when otherwise specified and in content retrieved from other bibliographic sources. 